\title{
Underreporting of Energy Intake in Iraqi People Living in the UK According to Body Weight
}

\author{
Wassan A. Ahmed, Waleed Al-Murrani, Gail A. Rees
}

School of Biomedical and Biological Sciences, University of Plymouth, Plymouth, UK.

Email: gail.rees@plymouth.ac.uk

Received December $11^{\text {th }}, 2011$; revised February $8^{\text {th }}, 2012$; accepted February $16^{\text {th }}, 2012$

\begin{abstract}
Previous studies have shown that underreporting of energy intake is common when assessing dietary intake, particularly in the overweight and obese. The aim of this study was to obtain an estimate of energy and macronutrient intake according to weight status and to investigate underreporting among Iraqi people living in the UK. Twenty eight adult volunteers ( $\mathrm{n}=16$ males) were recruited. Dietary intake was estimated 3 times using the 24 hour dietary recall tech- nique. Portion size was estimated using household measures and the Photographic Atlas of Food Portion Sizes. Energy and macronutrients estimations were calculated, and weight and height were measured to calculate Body Mass Index (BMI). Energy intake was compared to estimated basal metabolic rate (BMR) and the Goldberg equation was used to assess underreporting. Of the overall sample, $57.1 \%(n=16)$ and $21.4 \%(n=6)$ subjects were overweight and obese, respectively. The mean energy intakes were low for males $(1977 \mathrm{kcal} / \mathrm{d})$ and females $(1586 \mathrm{kcal} / \mathrm{d})$. The percentage of under-reporters was high (57.1\%) and this was higher in overweight and obese subjects $(68.1 \%)$ compared to those of normal weight (4.5\%). Overweight and obesity are common among well-educated Iraqi people. Underreporting of energy intake is common especially among overweight and obese Iraqi individuals.
\end{abstract}

Keywords: Energy; Obesity; Body Mass Index; Culture; Dietary Assessment

\section{Introduction}

The "24 hour dietary recall" is a food record method based on amounts in detail of all the food and drink actually consumed by an individual during a period of time in the recent past [1]. It is an in-depth interview conducted by a trained dietary interviewer to obtain accurate quantification of amounts of foods about everything the subject had to eat and drink, from midnight to midnight of the previous day or over the 24-hour period, either backward or forward. It is quick and easy to administer [2]. The important factors in this method to obtain complete information are the use of open-ended questions, a non-judgemental manner/a neutral attitude/ avoid asking questions in a manner that might influence the subject's responses, and the use of key questions and memory aids [3].

In this study, the repeat 24 hour dietary recall method was chosen over other dietary assessment methods because it was shown by the Low Income Diet and Nutrition Survey in UK [4], to be more acceptable to low income groups and ethnic minorities than a food frequency questionnaire or food diary. There is less need to write English for people who have English as a second language and it is less burden for respondents than other methods.
Misreporting, particularly in the form of underreporting, is common but varies between research methodologies and sampled populations [5-10]. Under recording of energy intake has been a well-known problem in measuring food intake through self-reporting methodologies such as the 24-hour diet recall, especially among overweight people [6,11-17] and women [18,19]. The frequency of underreporting of energy intake has been documented in different ethnic groups but not in those of Middle Eastern origin. Thus, the present study focused on a Middle Eastern group and aimed to obtain an estimate of energy and macronutrient intake according to weight status of Iraqi people living in the UK.

\section{Subjects and Methods}

A total of 28 participants were recruited through the University of Plymouth. The Human Ethics Committee of the Faculty of Science/University of Plymouth approved the study protocol. Prior to the study, each participant provided written informed consent to participate. Participants were given an explanation of the 24 hour recall; were informed of their right to anonymity and to withdraw their data if wished. At the end of the study participants were given feedback on their diet. 


\subsection{Anthropometric Data}

Height $(\mathrm{cm})$ was recorded to the nearest 0.5 centimeter using a stadiometer, and weight $(\mathrm{kg})$ was measured to nearest 0.1 kilogram using a balance scale. Weight status was defined by calculating Body Mass Index (BMI) which is computed as body weight $(\mathrm{kg})$ divided by height squared $\left(\mathrm{m}^{2}\right)$. The WHO-BMI standards [20] were adopted to define obesity: $<18.5 \mathrm{~kg} / \mathrm{m}^{2}=$ Underweight; 18.5 $24.9 \mathrm{~kg} / \mathrm{m}^{2}=$ normal weight; $25-29.9 \mathrm{~kg} / \mathrm{m}^{2}=$ overweight; $30+\mathrm{kg} / \mathrm{m}^{2}=$ obese.

\subsection{Dietary Recall}

Dietary intake of subjects was obtained using the 24 hour recall technique on three random days (including one weekend day) within a 10 day period. The environment was made comfortable by keeping the desk neat, choosing a private and quiet location, away from distractions, to help participants recall amounts/portions. Participants were asked to recall the food and drink consumed, food preparation methods, recipe ingredients, brand name of commercial products, use of dietary supplements, how much was consumed, time it was consumed, how it was served, and specific information of the food (low fat, etc.).

To estimate portion size, both interviewer and each subject used household measures, which were converted to grams with the use of the food portion sizes book. The Photographic Atlas of Food Portion Sizes [21]: a user's guide to the photographic atlas [22] was used to assess amounts of meals not estimated by spoons etc. Energy and macronutrients estimations were calculated using CompEat nutritional analysis programme [23].

\subsection{Assessment of Energy Requirements}

Basal Metabolic Rate (BMR) for each individual was calculated using Schofield [24] prediction equations, adopted by the FAO/WHO/UNU report (2004), based on age and gender. The ratios of the energy intake (EI)/estimated Basal Metabolic Rate (BMR) were calculated for each subject to evaluate underreporting. Subjects were classified as "energy under-reporters" when the ratio of reported energy intake to estimated Basal Metabolic Rate $($ EI/BMR $)<1.14$ according to the Goldberg et al. [25] cutoff limits. Participants with EI/BMR > 2.4 were classified as "energy over-reporters" based on the suggested range of the maximum energy for sustainable lifestyle which is between 2.0 - 2.4 [26]. Those with EI/BMR between 1.14 and $\leq 2.4$ were classified as "acceptable energy reporters".

\section{Results}

\subsection{Age and Anthropometric Data}

Table 1 shows the anthropometric characteristics of the
Table 1. Anthropometric data of the sample according to gender.

\begin{tabular}{ccc}
\hline Variables & Males $(\mathbf{n}=\mathbf{1 6})$ & Females $(\mathbf{n}=\mathbf{1 2})$ \\
\hline Weight (kg) & $83.3 \pm 17.3$ & $70.3 \pm 10.3$ \\
Height (cm) & $170.7 \pm 7.9$ & $158.4 \pm 3.4$ \\
BMI (kg/m $\left.\mathbf{m}^{2}\right)$ & $28.2 \pm 5.5$ & $27.6 \pm 3.4$ \\
BMI Distribution (\%) & & \\
$\mathbf{1 8 . 5}$ - 24.9 (normal) & 25 & 16.5 \\
$\mathbf{2 5}$ - 29.9 (overweight) & 50 & 67.0 \\
$\mathbf{3 0}$ and above (obese) & 25 & 16.5 \\
\hline
\end{tabular}

Data are expressed as mean $\pm \mathrm{SD}$.

study sample. The mean age was $39.8( \pm 11.9)$ years (range 27 - 70) in males and $36.5( \pm 11.7)$ years (range 22 - 64) in females. All subjects were from Iraq and the majority of them were post-graduate students in the University of Plymouth and their families. According to WHO-BMI classifications $16(57.1 \%)$ and $6(21.4 \%)$ subjects were overweight and obese, respectively.

\subsection{Energy and Macronutrients Intake}

The average intake of energy and macronutrient are detailed in Table 2 for males and females. Although intakes of energy, protein, carbohydrate and fat were higher in males than females, the differences did not meet statistical significance (Table 2).

While protein intakes are higher than the dietary reference values (DRV), the energy intake is lower.

\subsection{Assessment of Underreporting}

Comparing EI with BMR, using the Goldberg Equation cut-off points, $57.1 \%$ were under-reporters. The chisquare with one degree of freedom $\left(x^{2} 1\right)$ showed no significant differences between the number of males and females underreporting, although the rate of underreporting in males was $50 \%$, while in females was $66.6 \%$ (Table 3).

For those who were overweight or obese, $68.1 \%$ of them were classified as under-reporters, while just 3.5\% of normal weight subjects were under-reporters. Furthermore, the estimated ratios of underreporting were 58.3\% and $80 \%$ among overweight and obese males and females, respectively, but this difference was not statistically significant.

Although no differences were found in mean daily intake of energy, protein, carbohydrate and fat between normal and overweight subjects, the normal weight group reported higher intakes of energy (by 16.7\%), carbohydrates (by 10.5\%) and fat (by 22.3\%) (Table 4). 
Table 2. Daily energy and macronutrient intake (mean \pm SD) of the sample compared to DRV $^{*}$ according to gender.

\begin{tabular}{|c|c|c|c|c|c|}
\hline \multirow{2}{*}{ Energy and macronutrients } & \multicolumn{2}{|c|}{ Males (n = 16) } & \multicolumn{2}{|c|}{ Females $(n=12)$} & \multirow{2}{*}{$\begin{array}{c}P \text { value between } \\
\text { males and females }\end{array}$} \\
\hline & Mean \pm SD & DRV & Mean \pm SD & DRV & \\
\hline Energy (kcal) & $1977.1 \pm 575$ & \multirow[b]{2}{*}{2550 (kcal) } & $1585.7 \pm 556$ & & \multirow[b]{2}{*}{0.08} \\
\hline \%Total energy compared to $\mathrm{DRV}^{*}$ & $77.5 \%$ & & & 1940 (kcal) & \\
\hline Protein (g) & $78.2 \pm 24.1$ & $55.5(\mathrm{~g})$ & $66.8 \pm 20.2$ & $45.0(\mathrm{~g})$ & \multirow{2}{*}{0.18} \\
\hline \% Energy as protein compared to DRV & $15.6 \%$ & $15 \%$ & $16.3 \%$ & $15 \%$ & \\
\hline Carbohydrates & $255.9 \pm 70.5$ & - & $203.8 \pm 71.6$ & - & \multirow{2}{*}{0.06} \\
\hline \% Energy as carbohydrates compared to DRV & $51.0 \%$ & $50 \%$ & $49.8 \%$ & $50 \%$ & \\
\hline Fat & $74.3 \pm 35.2$ & - & $61.4 \pm 29.5$ & - & \multirow{2}{*}{0.30} \\
\hline \% Energy as fat compared to DRV & $33.3 \%$ & $35 \%$ & $33.7 \%$ & $35 \%$ & \\
\hline
\end{tabular}

*Dietary Reference Values for Food, Energy and Nutrients for the UK [33].

Table 3. Energy intake and basal metabolic rate of the sample according to gender.

\begin{tabular}{|c|c|c|}
\hline Variables & Males $(n=16)$ & Females $(n=12)$ \\
\hline EI'(kcal) & $1977 \pm 574.8$ & $1585 \pm 556.3$ \\
\hline EI /BMR ratio & $1.08 \pm 0.36$ & $1.12 \pm 0.36$ \\
\hline Ratio of underreporting/Total (\%) & 50 & 66.6 \\
\hline Ratio of underreporting (overweight)/Total (\%) & 58.3 & 80 \\
\hline
\end{tabular}

${ }^{*}$ Energy Intake; ${ }^{* *}$ Basal Metabolic Rate; Data are expressed as mean $\pm \mathrm{SD}$.

Table 4. Energy and nutrients intake of the sample categorized according to BMI.

\begin{tabular}{ccccc}
\hline Energy and macronutrients & Normal weight $(\mathbf{n}=\mathbf{6})$ & Overweight/obese $(\mathbf{n}=\mathbf{2 2})$ & \% relative differences & P value \\
\hline Energy (Kcal) & $2038 \pm 733.0$ & $1747.0 \pm 548.8$ & 16.7 & 0.40 \\
Protein (g) & $71.3 \pm 25.8)$ & $73.9 \pm 22.5$ & 0.03 & 0.83 \\
Carbohydrate (g) & $252.3 \pm 91.2$ & $228.4 \pm 70.7$ & 10.5 & 0.57 \\
Fat (g) & $80.3 \pm 38.7$ & $65.7 \pm 31.5$ & 22.3 & 0.42 \\
\hline
\end{tabular}

Data are expressed as mean $\pm \mathrm{SD}$.

\section{Discussion}

This study found that 22 of 28 (78.5\%) of a well-educated sample of Iraqi adults were overweight or obese. In a larger study of 242 Middle Eastern people living in Plymouth and London who reported their heights and weights, $49 \%$ of males and $43.8 \%$ of females were overweight or obese [27]. This larger study included people from different countries and of lower educational attainment.

The mean energy intake for the group was substantially lower than the UK estimated average requirement for energy intake which is likely to indicate underreporting.
The percentage of females underestimating energy intake was greater than males, although this was not statistically significant. This might be attributed to the small sample size and the high variability of the measurements. Similar findings have also been reported by other researchers [5,7-9,28,29]. Women compared to men, tend to be more preoccupied about weight, food and dieting; therefore, they are more prone to be embarrassed about their dietary intake and thus, more prone to underreport [30]. It seems this may also be true for women from Iraq.

In comparison to other groups where the 24 hour dietary recall has been used to estimate energy intake, the percentage of under-reporters in this study was higher (50\% males and $66.6 \%$ females) than what was reported 
among a US population ( $18 \%$ males, $28 \%$ females) [18] and Swedish individuals ( $44 \%$ males and $47 \%$ females) [7].

The percentage of under-reporters was higher in the overweight and obese $(68 \%)$ in both males and females compared to those of normal weight (16.6\%). These results seem to agree with the general outcome of other studies that overweight and obese individuals tend to underreport energy intake [5-7,10,28,29,31]. Heitmann and Lissner [32] found that obese Danish citizens tend to underreport fatty foods and foods rich in carbohydrates rather than underreport their total dietary intake. In addition, snack-type foods may be preferentially forgotten when obese people omit food items in dietary reporting.

This sample included a small number of well-educated Iraqi subjects and their families and does therefore not represent other Middle Eastern groups or those of lower educational attainment.

Underreporting of habitual food intake had an effect on the results for energy and macronutrients intake and in reality intakes would be higher especially in the overweight and obese group. The use of Compeat software program may have introduced some minor errors as it does not contain all the food items and brand names of Middle Eastern traditional diets. However care was taken to analyse recipes using basic ingredients to provide as accurate nutritional analysis as possible.

Finally, it is worth noting that it is not clear how well the Schofield equation predicts BMR for Middle Eastern people. Therefore, further research is needed to validate this and to explore levels of energy expenditure in this group.

\section{Conclusion}

In conclusion, more than three quarters of the sample (78.5\%) were overweight or obese. Underreporting of energy and macronutrient intake is common among overweight and obese individuals from Iraq.

\section{Acknowledgements}

We would like to thank all the participants who took part in this study for their co-operation and time.

\section{Conflicts of Interests, Source of Funding and Authorship}

All authors report that they have no conflict of interest. The study was funded by the Ministry of Higher Education and Scientific Research, Iraq. All authors were involved in the design of the study. WAA collected the data and undertook the nutritional analysis. GR supervised the data collection and nutritional analysis. WAM supervised the statistical analysis. All authors contributed to the manuscript and have read and approved the final version.

\section{REFERENCES}

[1] R. D. Lee and D. C. Nieman, "Nutritional Assessment," 4th Edition, McGraw-Hill Publishing Co, Boston, 2007.

[2] M. A. Eastwood, "Principles of Human Nutrition," 2nd Edition, Blackwell Science, Oxford, 2003.

[3] M. Buzzard, "24-Hour Dietary Recall and Food Record Methods," In: W. Willett, Ed., Nutritional Epidemiology, Oxford University Press, Oxford, 1998, pp. 50-73.

[4] Food Standards Agency, "Low Income Diet and Nutrition Survey," 2007.

http://www.food.gov.uk/science/dietarysurveys/lidnsbran $\mathrm{ch} /$

[5] P. Ferrari, N. Slimani, A. Ciampi, A. Trichopoulou, A. Naska, C. Lauria, F. Veglia, H. Bueno-de-Mesquita, M. Ocké, M. Brustad, T. Braaten, M. José Tormo, P. Amiano, I. Mattisson, G. Johansson, A. Welch, G. Davey, K. Overvad, A. Tjønneland, F. Clavel-Chapelon, A. Thiebaut, J. Linseisen, H. Boeing, B. Hemon and E. Riboli, "Evaluation of Under- and Overreporting of Energy Intake in the 24-Hour Diet Recalls in the European Prospective Investigation into Cancer and Nutrition (EPIC)," Public Health Nutrition, Vol. 5, No. 6b, 2002, pp. 1329-1345. doi:10.1079/PHN2002409

[6] D. W. Heerstrass, M. C. Ocke, H. B. Bueno-de-Mesquita, P. H. M. Peeters and J. C. Seidall, "Underreporting of Energy, Protein and Potassium Intake in Relation to Body Mass Index," International Journal of Epidemiology, Vol. 27, No. 2, 1998, pp. 186-193. doi:10.1093/ije/27.2.186

[7] G. Johansson, Å. Wikman, A.-M. Åhrén, G. Hallmans and I. Johansson, "Underreporting of Energy Intake in Repeated 24-Hour Recalls Related to Gender, Age, Weight Status, Day of Interview, Educational Level, Reported Food Intake, Smoking Habits and Area of Living," Public Health Nutrition, Vol. 4, No. 4, 2001, pp. 919-927. doi:10.1079/PHN2001124

[8] S. S. Jonnalagadda, D. C. Mitchell, H. Smiciklas-Wright, K. B. Meaker, N. V. Heel, W. Karmally, A. G. Ershow and P. M. Kris-Etherton, "Accuracy of Energy Intake Data Estimated by a Multiplepass, 24-Hour Dietary Recall Technique," Journal of the American Dietetic Association, Vol. 100, No. 3, 2000, pp. 303-311. doi:10.1016/S0002-8223(00)00095-X

[9] S.-H. Kye, "Underestimation of Energy Intake Using 24-Hour Recall by Korean Urban Elders," Ecology of Food and Nutrition, Vol. 43, No. 4, 2004, pp. 279-293. doi:10.1080/03670240490454697

[10] H. A. Park, J. S. Lee and L. H. Kuller, "Underreporting of Dietary Intake by Body Mass Index in Premenopausal Women Participating in the Healthy Women Study," Nutrition Research and Practice, Vol. 1, No. 3, 2007, pp. 231-236.

[11] R. Ballard-Barbash, I. Graubard, S. M. Krebs Smith, A. Schatzkin and F. E. Thompson, "Contribution of Dieting to the Inverse Association between Energy Intake and Body Mass Index," European Journal of Clinical Nu- 
trition, Vol. 50, 1996, pp. 98-106.

[12] R. R. Briefel, M. A. McDowell, K. Alaimo, C. R. Caughman, A. L. Bischof, M. D. Carroll and C. L. Johnson, "Total Energy Intake of the US Population: The Third National Health and Nutrition Examination Survey, 1988-1991," The American Journal of Clinical Nutrition, Vol. 62, 1995, pp. 1072S-1080S.

[13] M. Fogelholm, S. Männistö, E. Vartiainen and P. Pietinen, "Determinants of Energy Balance and Overweight in Finland 1982 and 1992," International Journal of Obesity, Vol. 20, No. 2, 1996, pp. 1097-1104.

[14] R. C. Klesges, L. H. Eck and J. W. Ray, "Who UnderReports Dietary Intake in a Dietary Recall? Evidence from the Second National Health and Nutrition Examination Survey," Journal of Consulting and Clinical Psychology, Vol. 63, No. 3, 1995, pp. 438-444. doi:10.1037/0022-006X.63.3.438

[15] S. W. Lichtman, K. Pisarska, E. R. Berman, M. Pestone, H. Dowling, E. Offenbacher, H. Weisel, S. Heshka, D. E. Matthews and S. B. Heymsfield, "Discrepancy between Self-Reported and Actual Caloric Intake and Exercise in Obese Subjects," The New England Journal of Medicine, Vol. 327, No. 27, 1992, pp. 1893-1898. doi:10.1056/NEJM199212313272701

[16] E. Rothenbreg, I. Bosaeus and B. Steen, "Evaluation of Energy Intake Estimated by a Diet History in Three Free-Living 70 Year Old Populations in Gothenburg, Sweden," European Journal of Clinical Nutrition, Vol. 51, 1997, pp. 60-66. doi:10.1038/sj.ejcn.1600363

[17] W. T. Smith, K. L. Webb and P. F. Heywood, "The Implications of Underreporting in Dietary Studies," Australian Journal of Public Health, Vol. 18, 1994, pp. 311-314. doi:10.1111/j.1753-6405.1994.tb00250.x

[18] R. R. Briefel, C. T. Sempos, M. A. McDowell, S. Chien and K. Alaimo, "Dietary Methods Research in The third National Health and Nutrition Examination Survey: Underreporting of Energy Intake," The American Journal of Clinical Nutrition, Vol. 65, 1997, pp. 1203S-1209S.

[19] M. A. Mendez, S. Wynter, R. Wilks and T. Forrester, "Under- and Over-Reporting of Energy Is Related to Obesity, Lifestyle Factors and Food Group Intakes in Jamaican Adults," Public Health Nutrition, Vol. 7, No. 1, 2004, pp. 9-19. doi:10.1079/PHN2003508

[20] WHO, "Global Database on Body Mass Index. World Health Organization in: An Interactive Surveillance Tool for Monitoring Nutrition Transition," Geneva, 2009. http://www.who.int/bmi/index.jsp?introPage=intro_3.htm 1

[21] M. Nelson, M. Atkinson and J. Meyer, "A Photographic Atlas of Food Portion Sizes," Food Standards Agency,
London, 1997.

[22] M. Nelson, M. Atkinson and J. Meyer, "Food Portion Sizes: A User's Guide to the Photographic Atlas," Food Standards Agency, London, 1997.

[23] CompEat, Nutritional Analysis Software, in, Nutrition Systems, Banbury. Oxon. England, 2003.

[24] W. N. Schofield, "Predicting Basal Metabolic Rate, New Standards and Review of Previous Work," Human Nutrition. Clinical Nutrition, Vol. 39, Suppl. 1, 1985, pp. 5-41.

[25] G. R. Goldberg, A. E. Black, S. A. Jebb, T. J. Cole, P. R. Murgatroyd, W. A. Coward and A. Prentice, "Critical Evaluation of Energy Intake Data Using Fundamental Principles of Energy Physiology: 1. Derivation of Cut-Off Limits to Identify Under-Recording," European Journal of Clinical Nutrition, Vol. 45, No. 12, 1991, pp. 569-581.

[26] FAO/WHO/UNU, "Human Energy Requirements," Food and Agriculture Organization and Nutrition Technical Report Series No. 1, FAO, Rome, 2004, pp. 1-103.

[27] W. A. Ahmed, "Vitamin D Intake of People from the Middle East living in the UK," Biological Sciences, MPhil Thesis, University of Plymouth, Plymouth, 2009.

[28] L. Johansson, K. Solvoll, G. E. Bjorneboe and C. A. Drevon, "Under- and Overreporting of Energy Intake Related to Weight Status and Lifestyle in a Nationwide Sample," The American Journal of Clinical Nutrition, Vol. 68, 1998, pp. 266-274.

[29] M. Yannakoulia, D. B. Panagiotakos, C. Pitsavos, E. Bathrellou, C. Chrysohoou, Y. Skoumas and C. Stefanadis, "Low Energy Reporting Related to Lifestyle, Clinical, and Psychosocial Factors in a Randomly Selected Population Sample of Greek Adults: The ATTICA Study," Journal of the American College of Nutrition, Vol. 26, No. 4, 2007, pp. 327-333.

[30] J. I. Macdiarmid and J. E. Blundell, "Dietary UnderReporting: What People Say about Recording Their Food Intake," European Journal of Clinical Nutrition, Vol. 51, No. 3, 1997, pp. 199-200. doi:10.1038/sj.ejen.1600380

[31] L. A. J. L. M. Braam, M. C. Ocke, H. B. Bueno-deMesquita and J. C. Seidell, "Determinants of ObesityRelated Underreporting of Energy Intake," American Journal of Epidemiology, Vol. 147, No. 11, 1998, pp. 1081-1086.

[32] B. L. Heitmann and L. Lissner, "Dietary Underreporting by Obese Individuals-Is It Specific or Non-Specific?" British Medical Journal, Vol. 14, 1995, pp. 986-989.

[33] Department of Health, "Dietary Reference Values for Food Energy and Nutrients for the United Kingdom," Report on Health and Social Subjects 41, 1991. 